\title{
Design and Study of Compact and Wideband Microstrip U-Slot Patch Antenna for Wi-Max Application
}

\author{
Sukhbir Kumar ${ }^{1}$, Hitender Gupta ${ }^{2}$ \\ ${ }^{I}$ (ECE Department,SDDIET,Kurukshetra University,India) \\ ${ }^{2}$ (ECE Department,SDDIET,Kurukshetra University,India)
}

\begin{abstract}
Microstrip patch antennas are strong candidates for use in many wireless communication applications. This paper proposes the use of a patch antenna with U-shaped slot to achieve wideband application with very low return loss. The objective of this paper is to design, construct and fabricate microstrip antennas suitable for Wi-Max application that centred at frequency $5.25 \mathrm{GHz}$. The antenna must operate within the band of $5.25 \mathrm{GHz}$ band. This band is currently being used for industrial, medical and scientific applications. The antenna is proposed to be used as a transmitting as well as receiving antenna in wireless network and the mentioned applications. A thick substrate with finite ground dimensions broadens the bandwidth of the antenna. The proposed antenna reduced the return loss as well as increases the bandwidth of the antenna.
\end{abstract}

Keywords - Wideband Antenna, Patch Antenna, Finite Ground, Wi-Max.

\section{INTRODUCTION}

Now a days patch antenna with high permitivity material substrate are used for wireless networking application. Modern life depends so much on wireless technologies that one can no longer afford to be off-line for long, even during flights. Although present regulations do not allow the use of wireless devices, the aircraft industry has already begun efforts to introduce in-flight wireless connectivity. In the past two and a half decades, many techniques have been developed to broaden the impedance bandwidth of probe feed microstrip patch antennas. In particular, the U-slot patch [1] enable a single patch single layer microstrip antenna to attain over 30\% impedance bandwidth. The use of thick and low permittivity substrates is the main reason for achieving wide impedance bandwidth. In this context, the present study investigated the possibility of designing a wireless antenna catering to applications at $5.15-5.35 \mathrm{GHz}$, making use of typical panel materials employed in such an environment. A wide-band anteena with frequency $5.15-5.85 \mathrm{GHz}$ bands would meet the requirements for all the above applications.

Microstrip patch antenna is widely considered to be suitable for many wireless applications, even though it usually has a narrow bandwidth [1]. To meet the above requirements, two individually challenging modifications may have to be combined to design a microstrip antenna with wideband operation [1]. Several broad banding techniques for microstrip antennas are widely known, prominent among them are the use of stacked patches or use of parasitic patches. The stacked patch antennas have multilayer structure consisting of several parasitic radiating elements placed one above the other and above the driven element. However this approach has the inherent disadvantage of increased overall thickness and issues related to aligning various layers precisely. The second approach uses patch antenna closely surrounded by parasitic patches. The structure looks like a coplanar parasitic subarray. This approach, although thin, the antenna occupies considerable lateral area.

Microstrip antennas (MSA) have some good features, like low cost, low profile. Due to this Microstrip antennas (MSA) are well suited for WLAN/Wi-MAX application systems. Microstrip antennas (MSA) have some disadvantages, like narrow bandwidth, low gain etc. Broad banding is the main problem, for solving this problem we propose new structures for devices that require more than one frequency band of operation [1]. Dual-band wireless phones have become popular recently because they allow using the one phone in two networks that have different frequencies. Tri-band phones have also gained popularity. Still, there exist more than three frequency bands used for wireless applications. The systems having multi-band operation require antennas that resonate at the specified frequencies. This only adds complexity to the antenna design problem. Recently, coplanar waveguide (CPW)-fed antenna has been more popular because of their many attractive features such as wider bandwidth, better impedance matching, and simplest structure of a single metallic layer, no soldering point, and easy integration with active devices or monolithic microwave integrated circuits. WiMAX technology is based on the IEEE 802.16 standard also called Broadband Wireless Access. The name WiMAX was created by the WiMAX forum which was formed in June 2001 to promote conformity and interoperability of the standard. The forum describes WiMAX as "a standards-based technology enabling the delivery of last mile wireless broadband access as an alternative to cable and DSL". There is no uniform global licensed spectrum for WiMAX, although the WiMAX Forum has published three licensed spectrum profiles: 2.5 
GHz (2.5-2.69 GHZ), 3.5 GHz (3.4-3.69 GHZ) and 5.5 GHz (5.25-5.85 GHZ). WiMAX provide the data rate upto70 Mbps over $50 \mathrm{Km}$. IEEE 802.16-2004 is often called IEEE 802.16d, since that was the working party that developed the standard. It is also frequently referred to as "fixed WiMAX" since it has no support for mobility. It replaced IEEE Standards 802.16-2001, 802.16c-2002, and 802.16a-2003. 802.16e-2005 is an amendment to 802.16-2004 and is often referred to in shortened form as 802.16e. It introduced support for mobility, amongst other things and is therefore also known as "mobile WiMAX". Compared to earlier approaches of broadbanding, the modification of this design approach offers the promise of saving space while meeting the antenna performance specifications.The proposed design results in an antenna with wideband operational band centered at $5.2 \mathrm{GHz}$. This design uses a customized 3-layer substrate material with a total thickness of $1.6 \mathrm{~mm}$.

\section{FINITE GROUND EFFECTS}

An analytical technique for the finite ground plane effect on radiation characteristics of a microstrip antenna. Theoretical results show that the gain of a circular patch antenna varies with the ground plane size and is maximum when the radius of the ground plane is 0.63_0. It was also found that the input impedance changes widely with the ground plane dimension and decreases with increase in the ground plane radius. The input impedance was found to vary widely with the ground plane dimensions, especially for electrically thick substrates. For a given substrate thickness, the surface wave loss was found to be maximum when the ground plane radius is approximately equal to $0.45 \_0$ and minimum when radius $\sim 0.70$. The resonant frequency also got slightly shifted with ground plane truncation. In his report, impedance bandwidth and radiation efficiency as functions of antenna position on a finite-sized ground plane were studied for a dualband U-shaped-slot PIFA (UPIFA). His results showed that radiation efficiency and impedance bandwidth are strongly dependent on the antenna location with respect to the ground plane. From his results, it appears that variation of the size of the finite ground plane seems to have similar effect on both U-slot and rectangular patch antennas. In 2004, R. Urban and C. Peixeiro [16] reported the effects of ground plane size on a microstrip antenna performance for small handsets. They also examined effects of small ground plane on bandwidth and gain of PIFA. (10)

\section{Antenna Design Procedure}

The geometry of a single patch antenna using u-slot with different finite ground dimension feed by microstrip feed line can be shown in Figure 1. The patch antenna is constructed on same dielectric substrate. The patch antenna is realized on FR 4 substrate and having a relative permittivity $(\varepsilon \boldsymbol{r})=4.98$, substrate of thickness $(\boldsymbol{h})=1.6 \mathrm{~mm}$ and loss tangent $(\tan \delta)=0.09$ and the microstrip feed line is realized on the same substrate layer.

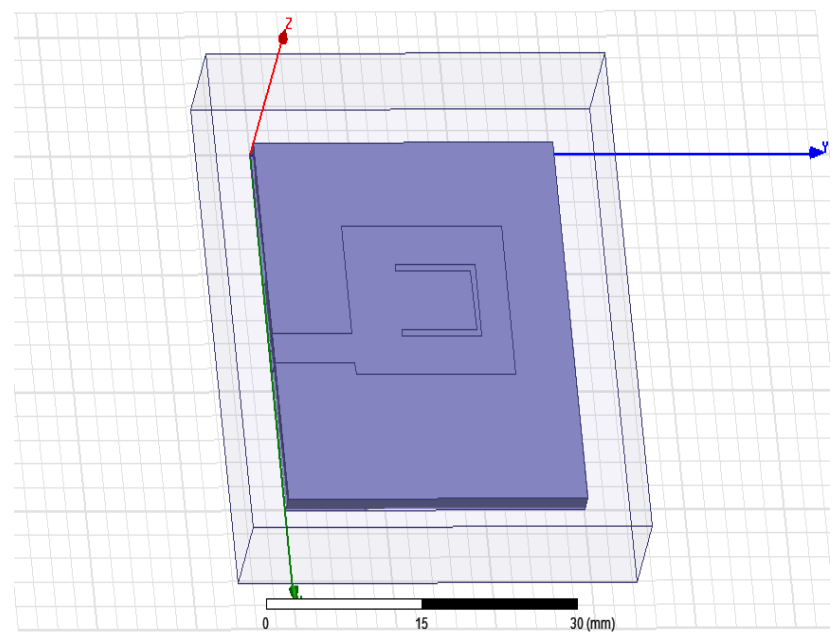

Figure 1: Design of Proposed Antenna

\section{Design Formulas To Calculate Dimensions Of Rectangular Microstrip Patch} ANTENNA

The width of the rectangular MSA is given by [7]:

$$
W=\frac{c}{2 f_{r} \sqrt{\frac{2}{\epsilon_{r}+1}}}
$$


Effective dielectric constant is given as [2]:

The length extension is given as [2]:

$$
\epsilon_{\text {reff }}=\frac{\epsilon_{r}+1}{2}+\frac{\epsilon_{r}-1}{2}\left[1+12 \frac{h}{W}\right]^{-\frac{1}{2}}
$$

$$
\Delta L=0.412 h \frac{\left(\epsilon_{r}+0.3\right)\left(\frac{W}{h}+0.264\right)}{\left(\epsilon_{r}-0.3\right)\left(\frac{W}{h}+0.8\right)}
$$

The actual length is given by [2]:

$$
L=\frac{c}{2 f_{r} \sqrt{\epsilon_{\text {reff }}}}-2 \Delta L
$$

The length and the width of the ground plane are given by[7]:

$$
\begin{aligned}
& W_{g}=6 h+W \\
& L_{g}=6 h+l
\end{aligned}
$$

Using the values given by TLM approximation, a model is built using HFSS.

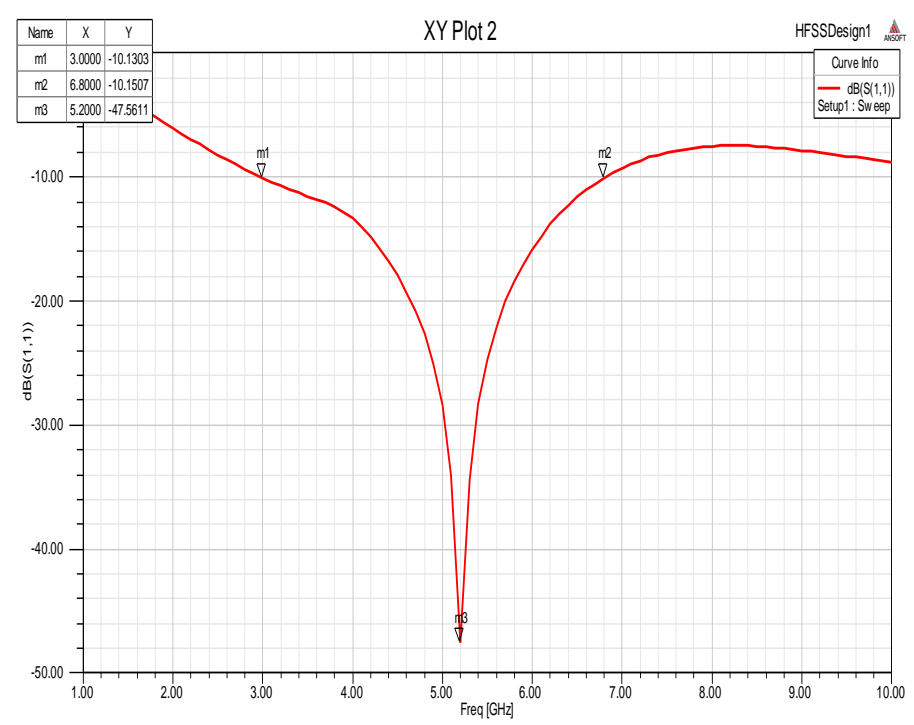

Figure 2: Return Loss of Proposed Antenna

Table 1.1: Dimensions of Proposed Antenna

\begin{tabular}{|l|l|}
\hline Parameters & Dimensions \\
\hline Substrate length $(\mathrm{mm})$ & 30 \\
\hline Substrate breath $(\mathrm{mm})$ & 30 \\
\hline Substrate thickness $(\mathrm{mm})$ & 1.6 \\
\hline $\begin{array}{l}\text { Dielectric constant of } \\
\text { substrate }\end{array}$ & 4.4 \\
\hline Tangent loss & 0.01 \\
\hline Patch length $(\mathrm{mm})$ & 12.5 \\
\hline Patch breath $(\mathrm{mm})$ & 16 \\
\hline Finite Ground length $(\mathrm{mm})$ & 30 \\
\hline Ground width $(\mathrm{mm})$ & 8 \\
\hline
\end{tabular}

\section{CONCLUSION}

This paper proposed a rectangular shaped patch with u-slot antenna for WI-MAX applications in this paper, a comprehensive review has been given of the u-slot patch antenna. Although, this antenna is best known for its wideband characteristics. This antenna is applicable for the WI-MAX application which is centered at frequency 5.20MHz. This antenna gives the good results in WI-MAX applications. 


\section{REFERENCES}

[1] V.Ratna Bhargavi,P.Poorna Priya,K.Pavan Kumar, Dr.Habibulla Khan, “ Gain Enhancement of V-slotted Triangular Shape Microstrip Patch Antenna for WiMax Applications" International Journal of Engineering Research and Applications (IJERA), vol. 2, issue 3, May-Jun 2012, pp.1187-1193

[2] L. Lolit Kumar Singh, Bhaskar Gupta, Partha P Sarkar, " A Review on Effects of Finite Ground Plane on Microstrip Antenna Performance” International Journal Of Electronics And Communication Engineering \& Technology (IJECET), Volume 3, issue 3, october- december (2012), pp. 287-292

[3] Indra Surjati, Yuli KN and Yuliastuti, “ Increasing Bandwidth Dual Frequency Triangular Microstrip Antenna For wimax Application” International Journal of Electrical \& Computer Sciences IJECS-IJENS Vol: 10 No: 06, 2010.

[4] Samvedna Srivastava, Prof. Rajesh Nema, Prof. Rajeev Kumar Thakur, "Micro-strip Patch Antenna on Glass Proxy Substrate for Infinite and Finite Ground Plane” International Journal of Scientific Engineering and Technology, Volume No.1, Issue No.4, pp : 1620, 01 Oct. 2012.

[5] S. L. S. Yang, K. F. Lee, and A. A. Kishk, “Design And Study Of Wideband Single Feed Circularly Polarized Microstrip Antennas”, Progress In Electromagnetics Research, PIER 80, 45-61, 2008

[6] B. Vedaprabhu and K. J. Vinoy, "An Integrated Wideband Multifunctional Antenna Using A Microstrip Patch With Two U-Slots" Progress In electromagnetics Research B, Vol. 22, 221-235, 2010

Books:

[7] Constantine A. Balanis (John Wiley \& Sons, Inc., Hoboken, New Jersey,2005). antenna theory analysis and design 